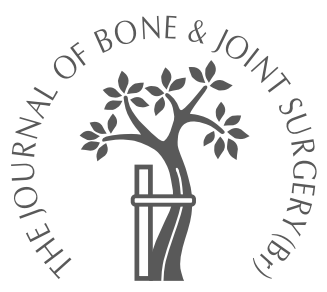

J. Hardes,

G. Gosheger,

L. Vachtsevanos,

C. Hoffmann,

H. Ahrens,

W. Winkelmann

From Westfaelische

Wilhelms-

Universitaet Münster,

Münster, Germany

and the University

Hospital of Wales, Cardiff, Wales

J. Hardes, MD, Registrar

G. Gosheger, MD,

Consultant

C. Hoffmann, MD

Registrar

H. Ahrens, MD, Registrar

W. Winkelmann, MD,

Professor

Department of Orthopaedics, University of Münster

Albert-Schweitzer-Strasse

33, 48149 Münster, Germany.

L. Vachtsevanos

University Hospital of Wales,

Cardiff, Wales CF10 3XQ, UK.

Correspondence should be sent to Dr J. Hardes; e-mail hardes@uni-muenster.de

(C)2005 British Editorial

Society of Bone and

Joint Surgery

doi:10.1302/0301-620X.87B3.

$14793 \$ 2.00$

$J$ Bone Joint Surg [Br]

2005;87-B:395-400.

Received 18 July 2003;

Accepted after revision

25 March 2004

\title{
Rotationplasty type BI versus type BIIIa in children under the age of ten years
}

\author{
SHOULD THE KNEE BE PRESERVED?
}

Type BI rotationplasty is currently indicated for children with tumours of the proximal femur whereas type Bllla rotationplasty is reserved for those in which the entire femur has to be removed. Our aim was to compare these two types of rotationplasty and determine whether the knee should be preserved in children with tumours of the proximal femur. We compared the post-operative complications, oncological outcome, range of movement, Enneking score and radiographs of six children, who had undergone type BI rotationplasty with those of 12 who had undergone type Bllla rotationplasty.

Patients with type BI rotationplasty had a mean Enneking score of 21.6 compared with 24.4 in those with type Bllla rotationplasty, and worse mean results in all of the parameters investigated. We conclude that type BI rotationplasty has a worse functional outcome and more complications than type Bllla rotationplasty in children under the age of ten years.

Rotationplasty can be used as an alternative to amputation in patients with malignant bone tumours of the proximal, distal or entire femur and proximal tibia. ${ }^{1,2} \mathrm{~A}$ further indication is maligant bone tumours in children under ten years of age as an alternative to an extendible endoprosthesis. ${ }^{3}$ It can also be performed as a second-line surgical procedure after failure, e.g. because of infection, of a limb-salvage procedure. $^{4-6}$

Rotationplasty was first performed by Borggreve in 1927 on a patient with a fused knee and consequent limb-length inequality secondary to tuberculosis. ${ }^{4,7}$ In 1950 , Van $\mathrm{Nes}^{8}$ used rotationplasty in patients with a congenital defect of the femur. Its application in the treatment of malignant bone tumours, however, was first described by Kristen, Knahr and Salzer in $1975^{9}$ and Salzer et al in $1981^{10}$ who used it as an alternative to above-knee amputation in a patient with osteosarcoma of the distal femur.

In 1986 a modification of the procedure by Winkelmann $^{1,3}$ allowed it to be used in patients with malignant tumours of the proximal femur with or without involvement of the hip as well as of the lower pelvis.

A further modification by Winkelmann described its use in patients with skip metastases or extensive femoral tumours, in which the whole femur had to be removed., ${ }^{2,3,6,11,12}$ He classified rotationplasty into two main types as follows: type $\mathrm{A}$, knee rotationplasties and type B, hip rotationplasties. ${ }^{3,13}$ Type A is subclassified into type AI for tumours of the distal femur and type AII for those of the proximal tibia. Type B is subclassified into types BI, BII and BIII. Type BI is indicated for malignant tumours of the proximal femur without involvement of the hip and involves replacement of the latter by the ipsilateral knee, which is rotated through $180^{\circ}$ and fixed to the pelvis where it functions as a hinge joint. Type BII hip rotationplasty is indicated for malignant tumours of the proximal femur with involvement of the lower pelvis, in which a lower internal hemipelvectomy is required. Finally, type BIII is performed in tumours which require complete resection of the femur and is further subdivided into type BIIIa for children and type BIIIb for adults. In type BIIIa, the hip is reconstructed by placing the rotated, lateral tibial condyle into the acetabulum after disarticulation of the knee and complete removal of the affected femur. In children, the lateral tibial condyle progressively remodels to resemble a new 'femoral head'. In adults, such remodelling does not occur and therefore an arthroplasty is used, hence type BIIIb rotationplasty.

We describe the long-term results of type BI and type BIIIa rotationplasty in children up to ten years of age. The main aim was to compare these two types of rotationplasty and determine which was the more appropriate for children and whether preservation of the knee was worthwhile. 


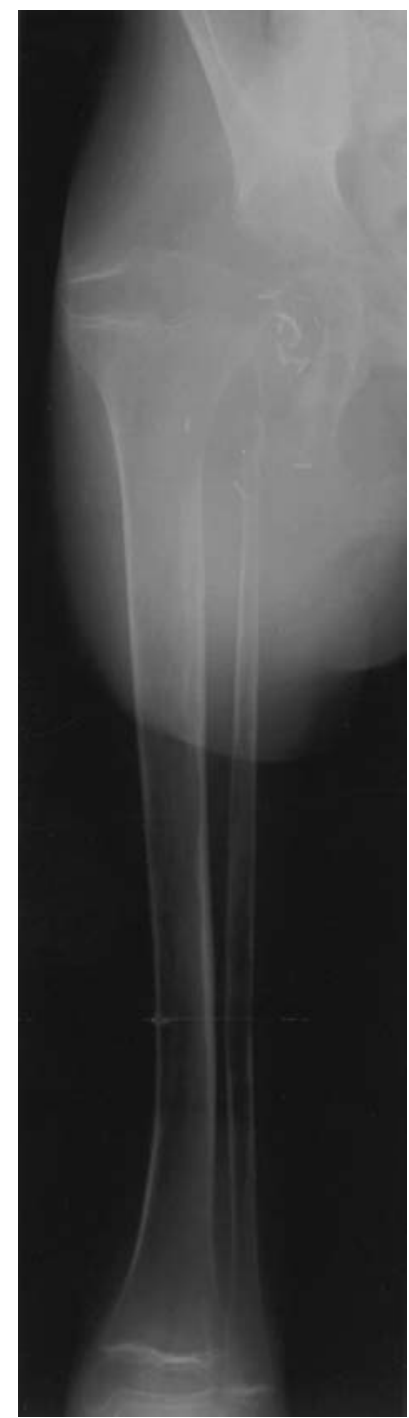

Fig. 1a

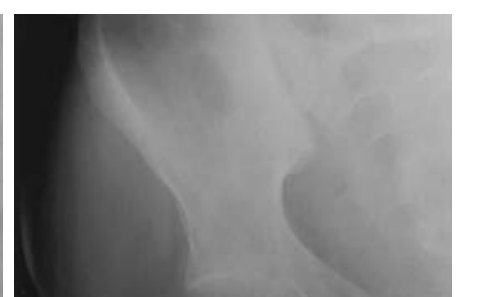

\section{Twelve patients were treated by type BIIIa rotationplasty} combined with chemotherapy. The mean age at operation was 5 years and 9 months $(2.8$ to 10.6$)$ and their mean follow-up 4 years and 10 months $(0.3$ to 9.8$)$. Five had an osteosarcoma (stage IIb in four and stage III in one), six had a Ewings sarcoma (stage IIb) and one a primitive neuroectodermal tumour (stage IIb). The tumour involved the entire femur in three patients, the proximal and diaphyseal femur in two, the proximal femur with a distal skip metastasis in one, the distal femur in one, diaphyseal femur in one, the distal femur with a proximal skip metastasis in one and the proximal femur in three. One patient (case 9) simultaneously suffered two pathological fractures of the proximal and distal right femur. Finally, one patient with a Ewing's sarcoma (case 13) suffered two pre-operative pathological fractures after radio- and chemotherapy with consequent femoral malrotation, limb shortening and palsy of the sciatic nerve.

The parameters used to assess the outcome were postoperative complications, oncological outcome, range of movement and functional score according to Hillmann et $\mathrm{al}^{12}$ and Enneking et al. ${ }^{14}$ In addition, anteroposterior (AP) and lateral radiographs were used to estimate the postoperative progress of the reconstructed joints.

The range of movement is that at the rotated knee in patients with type BI rotationplasty and recorded as degrees of flexion, extension, abduction, adduction and internal and external rotation at the 'neohip' in patients with type BIIIa. The range of movement was available for all the patients who underwent type BI rotationplasty, but it could not be measured in one patient with type BIIIa rotationplasty (case 15), who had an above-knee amputation because of post-operative complications. We have therefore compared the mean range of movement of all patients with type B1 with that of 11 with type BIIIa rotationplasty.

Radiological assessment of patients with type BI rotationplasty was based on the extent of the following degenerative changes in the reconstructed hip: joint-space narrowing, and the presence of osteophytes, subchondral sclerosis and cysts. Radiographs from patients with type BIIIa rotationplasty were further assessed with respect to the extent of remodelling of the tibial head and its degree of containment within the acetabulum.

The limited number of patients who undergo these two types of rotationplasty, made our sample size too small to allow a detailed statistical analysis. However, we have included all the patients who underwent these two types of rotationplasty in two University Hospitals over the last 20 years. 


\section{Results}

Post-operative complications. These are detailed in Table II. Complications occurred in three of the six patients, who underwent type BI rotationplasty. In one (case 2) there was loosening of the osteosynthesis, thrombosis of the venous anastomosis and haematoma and the patient required revision osteosynthesis, re-anastomosis and drainage of the haematoma on the first post-operative day. The osteosynthesis was removed ten months later. In another (case 5) there was a haematoma and embolism of the femoral artery requiring embolectomy on the day of the operation. The third patient (case 4) presented with delayed wound-healing and required debridement and repeat suturing.

Post-operative complications occurred in four of 12 patients who had undergone type BIIIa rotationplasty. One (case 11) developed a haematoma with temporary total paresis and sensory loss over the affected limb, which eventually recovered. The haematoma was drained on the first post-operative day. Subsequently, the patient developed shortening of $6.5 \mathrm{~cm}$ of the rotated limb which did not affect the clinical result. The second patient (case 9) had post-operative limb shortening of $2 \mathrm{~cm}$, which was of trivial clinical importance. The third patient (case 14) required a second procedure to shorten the proximal rotated fibula shortly after the initial operation. This patient also suffered a fracture of the proximal tibia two years after the operation. The fourth patient (case 15) developed a haematoma and compartment syndrome, requiring decompression on the first post-operative day. Despite this an above-knee amputation with sparing of the proximal tibia was required on the 12th post-operative day for progressive muscle necrosis.

Oncological outcome. One patient treated by type BI rotationplasty (case 6) had a stage-III Ewing's sarcoma and died two years and eight months after the operation from pulmonary and bone metastases. Two more patients (cases 1 and 4) had pulmonary metastases but are in remission. Thus, five of six patients who had type B1 rotationplasty had no evidence of recurrence of the tumour and were free from disease at follow-up. One of the 12 patients who had type BIIIa rotationplasty (case 18) had stage III osteosarcoma and died from metastases in the lung and proximal tibia approximately three months after operation. The remaining 11 patients had no evidence of recurrence and were free from disease at follow-up.

Range of movement. The mean flexion and extension of the reconstructed hip in patients with type BI rotationplasty was $55.8^{\circ}$ (40 to 70 ) and $0^{\circ}$, respectively, compared with a mean 'neohip' flexion of $82.7^{\circ}$ (60 to 110 ) and extension of $0^{\circ}$ in those with type BIIIa rotationplasty (Table II). Furthermore, patients with type BI rotationplasty did not have any abduction, adduction or internal or external rotation at the reconstructed hip. By contrast, type BIIIa patients had a mean abduction and adduction of $25.5^{\circ}$ (15 to 35) and $20^{\circ}$ (10 to 35 ) and a mean internal and external rotation of $18.4^{\circ}$ (10 to 40$)$ and $21.2^{\circ}$ (10 to 50$)$, respectively.

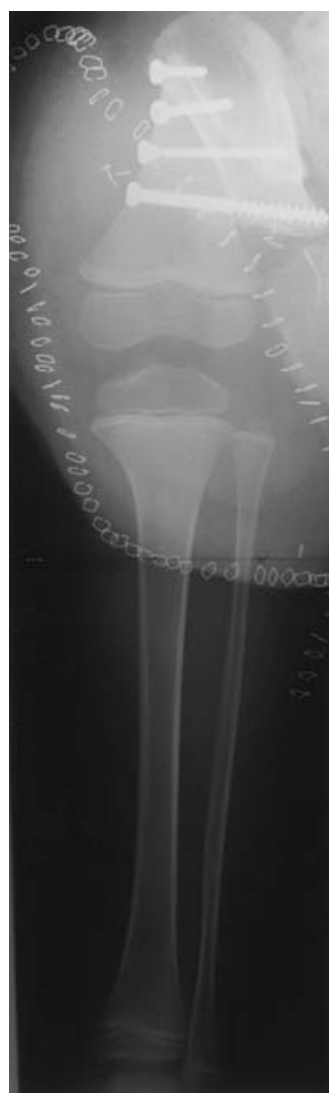

Fig. 2a

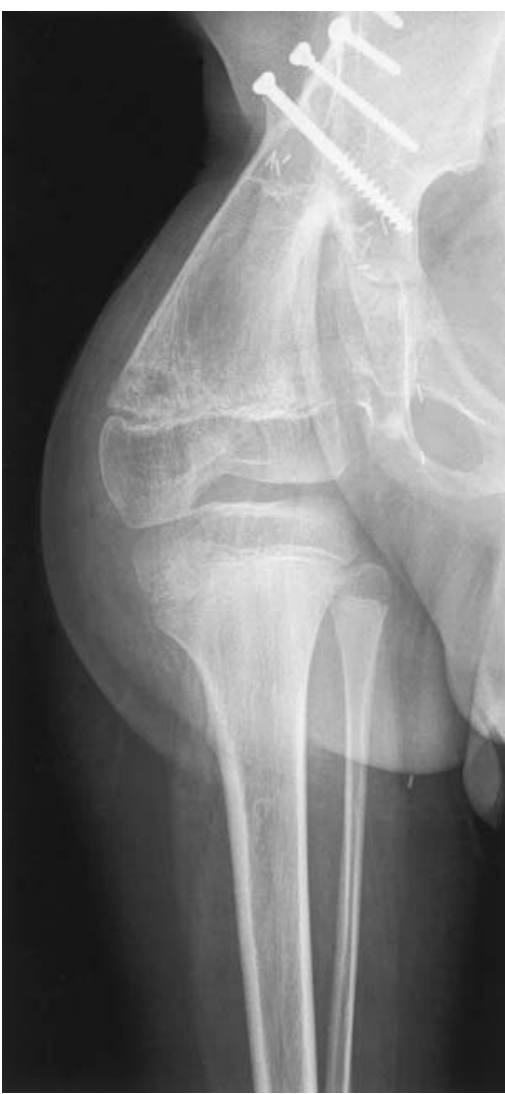

Fig. 2b
Case 5. AP radiographs of a boy aged four years and nine months with type $\mathrm{BI}$ rotationplasty, taken post-operatively and at follow-up nine years later showing a) good fusion of the osteosynthesis without any axis deviation and b) a hyperadduction deformity because of ossification of the medial aspect of the distal femoral growth plate, presumably caused by an altered distribution of load.

Enneking score. The mean Enneking score in the patients who underwent type BI rotationplasty was 20.2 of 30 (13 to 24) (Table II). One patient (case 6) was in a poor physical condition because of post-operative metastases and eventually died. If this patient was excluded the mean Enneking score in these patients rose to 21.6 of 30 (19 to 24), which represented $72 \%$ of normal function.

The mean Enneking score among the type BIIIa rotationplasty patients was 23.9 of 30 (19 to 27). However, assuming we excluded the patient who presented with walking difficulties because of pre-operative palsy of sciatic nerve (case 13) which was irrelevant to the type of rotationplasty offered, the mean Enneking score for these patients then rose to 24.4 of 30 (23 to 27 ), which denoted $81.3 \%$ of normal function (Table II). Enneking scores were not assigned to two patients (cases 15 and 18) because amputation was necessary in one (case 15) and the other (case 18) died from metastases shortly after the operation.

Radiological results. Moderate joint-space narrowing and subchondral sclerosis were seen in two of the six patients treated by type BI rotationplasty (cases 1 and 3). One 


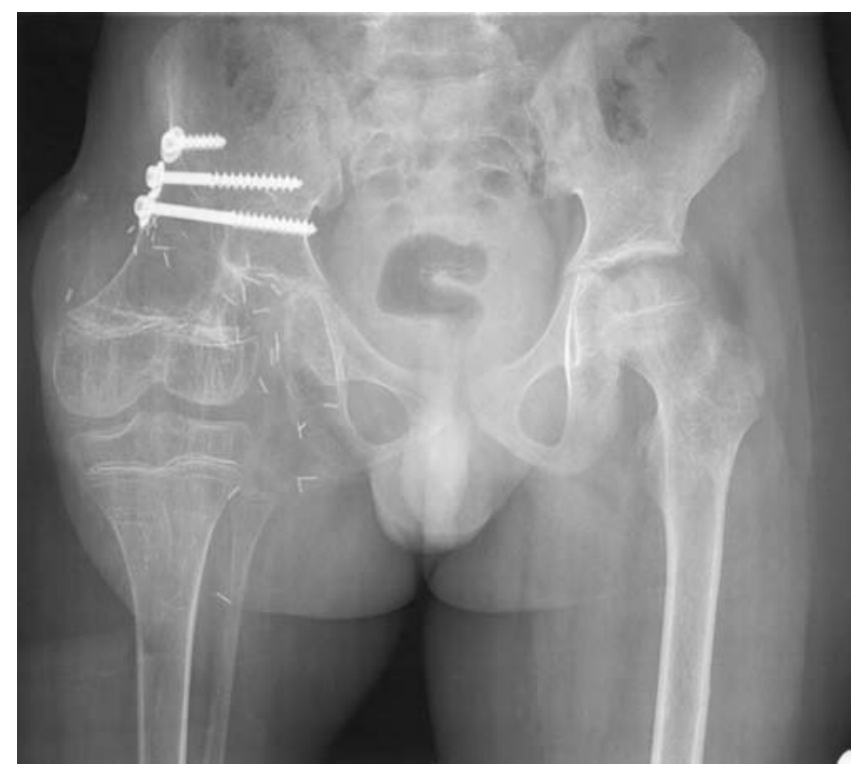

Fig. 3

Case 6. AP pelvic radiograph taken two years and eight months after a type $\mathrm{BI}$ rotationplasty in a boy aged eight years and seven months. There is stable osteosynthesis with no signs of axis deviation or loosening and a well-preserved knee without any evidence of degenerative joint disease.

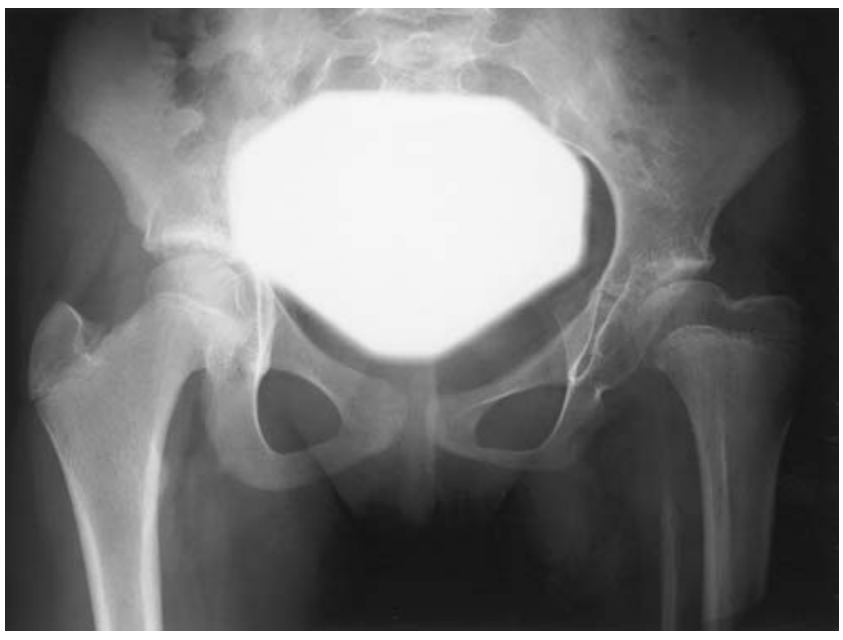

Fig. 4

Case 7. AP pelvic radiograph of an 11-year-old girl who had a type Bllla rotationplasty at the age of five years. Six years after operation, excessive remodelling has transformed the tibial head into the semblance of a normal femoral head and has remarkably improved its containment in the acetabulum.

patient (case 5) developed progressive hyperadduction of the distal femur (Fig. 2), while the radiographs of the remaining three patients (cases 2, 4 and 6) showed moderately demineralised bones with no signs of degenerative joint disease (Fig. 3).

Of the patients treated by type BIIIa rotationplasty, five had excellent radiological results (Fig. 4) with no evidence of degenerative disease and remarkable tibial remodelling and containment in the acetabulum (cases 7 to 9, 12 and 17). Another (case 16), who was aged 10.6 years at operation showed remarkably good remodelling of the 'neohip' (Fig. 1). Less impressive tibial remodelling was seen in six patients (cases 10 to 14 and 16). Two patients (cases 15 and 18) were not included in the assessment since one (case 15) had an above-knee amputation and the other (case 18) died from metastases three months after the operation.

\section{Discussion}

The improved prognosis of patients with malignant bone tumours achieved by the use of neoadjuvant chemotherapy underlines the importance of successful limb-salvage surgery. ${ }^{15}$ In children less than ten years of age, limb-salvage procedures using extendible endoprostheses carry the risk of numerous complications and re-operations. ${ }^{16}$ Rotationplasty has the advantage of being a single operation which does not usually require revision procedures and is associated with remarkably good function. ${ }^{2,11,17}$ It is therefore a good treatment option in children with malignant bone tumours of the lower limb.

Winkelmann ${ }^{1-3}$ developed type BI rotationplasty for tumours of the proximal femur and type BIIIa rotationplasty for those involving the entire femur in children. The idea underlying the use of type BI rotationplasty was that preservation of the knee could lead to improved post-operative function. However, the use of type BIIIa rotationplasty gives excellent functional results. The plasticity of the cartilaginous tibial plateau in children allows it to remodel and function like a femoral head., ${ }^{2,11}$ In our study, patients with a type BIIIa rotationplasty had a better range of movement at the reconstructed hip and a higher Enneking score, $81.3 \%$ compared with $72 \%$ in patients with type BI rotationplasty. The Enneking score was devised for use in adults but we felt it was the best score to use although it has not been validated in children. The lack of abduction, adduction and rotation in the hip as a result of fixation of the knee to the pelvis, restricted patients with a type BI rotationplasty in their activities of daily life. This did not apply to patients with type BIIIa rotationplasty, who had a useful range of abduction, adduction and rotation at the 'neohip'. Furthermore, type BIIIa rotationplasty appeared to be associated with fewer post-operative complications.

An additional problem of type BI rotationplasty is the difficulty of fixing the femur to the pelvis. Loosening of the osteosynthesis with consequent axis deviation can often lead to an increased stay in hospital and further re-admissions. In one patient (case 5) a hyperadduction deformity of the distal femur resulted in poor function for which a corrective osteotomy is planned. By contrast, no axis deviation was seen in the patients with type BIIIa rotationplasty.

The limb-length discrepancy which was sometimes seen in type BIIIa rotationplasty (cases 9 and 11) did not appear to be of clinical importance and was easily compensated for by the prosthesis. 
Table I. Details of the patients

\begin{tabular}{|c|c|c|c|c|c|c|c|c|c|}
\hline Case & Gender & $\begin{array}{l}\text { Type of } \\
\text { operation }\end{array}$ & $\begin{array}{l}\text { Age at } \\
\text { operation (yrs) }\end{array}$ & Diagnosis* & Localisationt & $\begin{array}{l}\text { Pre-operative } \\
\text { complications } \$\end{array}$ & Radiotherapy & Chemotherapy & $\begin{array}{l}\text { Follow-up } \\
\text { (mths) }\end{array}$ \\
\hline 1 & $M$ & $\mathrm{BI}$ & 9.2 & ES & Prox femur R & $F x$ & Yes & Yes & 111 \\
\hline 2 & $\mathrm{~F}$ & $\mathrm{BI}$ & 6.9 & ES & Prox femur L & $F x$ & No & Yes & 19 \\
\hline 3 & $\mathrm{~F}$ & $\mathrm{BI}$ & 9.2 & ES & Prox femur R & No & No & Yes & 148 \\
\hline 4 & $M$ & $\mathrm{BI}$ & 6.10 & os & Prox femur L & No & No & Yes & 45 \\
\hline 5 & $M$ & $\mathrm{BI}$ & 4.9 & ES & Prox femur R & No & Yes & Yes & 105 \\
\hline 6 & $M$ & $\mathrm{BI}$ & 8.7 & ES & Prox femur R & $\begin{array}{l}\text { Fx and } \\
\text { osteosynthesis }\end{array}$ & Yes & Yes & 32 \\
\hline 7 & $\mathrm{~F}$ & BIIla & 5.1 & os & Dist femur $L$ & No & No & Yes & 105 \\
\hline 8 & $\mathrm{~F}$ & BIIla & 4.1 & ES & Entire femur $\mathrm{R}$ & No & No & Yes & 74 \\
\hline 9 & $\mathrm{~F}$ & BIIla & 3.5 & ES & Entire femur R & Fx§ & No & Yes & 71 \\
\hline 10 & $M$ & BIIla & 4.3 & PNET & $\begin{array}{l}\text { Prox and diaph } \\
\text { femur } R\end{array}$ & No & No & Yes & 54 \\
\hline 11 & $\mathrm{~F}$ & Bllla & 9.8 & OS & Entire femur $\mathrm{R}$ & No & No & Yes & 57 \\
\hline 12 & $M$ & BIIla & 2.8 & ES & $\begin{array}{l}\text { Prox femur and } \\
\text { dist skip meta- } \\
\text { stases L }\end{array}$ & No & No & Yes & 116 \\
\hline 13 & M & BIIla & 8.0 & ES & Prox femur R & Fxף & Yes & Yes & 73 \\
\hline 14 & $\mathrm{~F}$ & BIIla & 3.1 & ES & Prox femur R & No & No & Yes & 30 \\
\hline 15 & M & Bllla & 3.11 & ES & Prox femur L & No & No & Yes & 13 \\
\hline 16 & $M$ & BIIla & 10.6 & os & $\begin{array}{l}\text { Prox and diaph } \\
\text { femur } \mathrm{R}\end{array}$ & No & No & Yes & 65 \\
\hline 17 & M & Bllla & 6.0 & OS & Dist and mid femur & No & No & Yes & 32 \\
\hline 18 & $\mathrm{~F}$ & Bllla & 9.8 & OS & $\begin{array}{l}\text { Dist femur and prox } \\
\text { skip metastases R }\end{array}$ & No & No & Yes & 3 \\
\hline
\end{tabular}

* ES, Ewing's sarcoma; OS, osteosarcoma; PNET, primitive neuroectodermal tumour

† Prox, proximal; dist, distal; diaph, diaphyseal; R, right; L, left

$\neq$ Fx, fracture

$\S$ pathological fractures of proximal and distal femur

If two pathological fractures with femoral malrotation, palsy of the sciatic nerve and limb-length discrepancy of $8 \mathrm{~cm}$

Table II. Post-operative function and results in the 18 patients

\begin{tabular}{|c|c|c|c|c|c|c|c|c|}
\hline \multirow[b]{2}{*}{ Case } & \multirow[b]{2}{*}{$\begin{array}{l}\text { Type of } \\
\text { operation }\end{array}$} & \multirow[b]{2}{*}{$\begin{array}{l}\text { Post-operative } \\
\text { complications }\end{array}$} & \multirow[b]{2}{*}{ Repeat operations } & \multirow[b]{2}{*}{$\begin{array}{l}\text { Disease } \\
\text { status* }\end{array}$} & \multicolumn{3}{|l|}{ Hip } & \multirow[b]{2}{*}{$\begin{array}{l}\text { Enneking } \\
\text { score }^{14}\end{array}$} \\
\hline & & & & & $\begin{array}{l}\text { Flexion/ } \\
\text { extension }\left({ }^{\circ}\right)\end{array}$ & $\begin{array}{l}\text { Abduction/ } \\
\left.\text { adduction ( }{ }^{\circ}\right)\end{array}$ & $\begin{array}{l}\text { Int/ext } \\
\text { rotation ( }{ }^{\circ} \text { ) }\end{array}$ & \\
\hline 1 & $\mathrm{BI}$ & None & None & NED & $45 / 0 / 0$ & $0 / 0 / 0$ & $0 / 0 / 0$ & $23 / 30$ \\
\hline 2 & $\mathrm{BI}$ & $\begin{array}{l}\text { Loosening of osteosynthesis, } \\
\text { haematoma and thrombosis }\end{array}$ & $\begin{array}{l}\text { Re-ostosynthesis and re-anasto- } \\
\text { mosis. Osteosynthesis removed }\end{array}$ & NED & $40 / 0 / 0$ & $0 / 0 / 0$ & $0 / 0 / 0$ & $19 / 30$ \\
\hline 3 & $\mathrm{BI}$ & None & None & NED & $50 / 0 / 0$ & $0 / 0 / 0$ & $0 / 0 / 0$ & $23 / 30$ \\
\hline 4 & $\mathrm{BI}$ & Wound-healing problem & Debridement and repeat suturing & NED & $70 / 0 / 0$ & $0 / 0 / 0$ & $0 / 0 / 0$ & $24 / 30$ \\
\hline 5 & $\mathrm{BI}$ & $\begin{array}{l}\text { Haematoma and embolism of } \\
\text { the femoral artery }\end{array}$ & Embolectomy on the same day & NED & $60 / 0 / 0$ & $0 / 0 / 0$ & $0 / 0 / 0$ & $19 / 30$ \\
\hline 6 & $\mathrm{BI}$ & None & None & DOD & $70 / 0 / 0$ & $0 / 0 / 0$ & $0 / 0 / 0$ & $13 / 30 \dagger$ \\
\hline 7 & BIIla & Tibial greenstick fracture & None & NED & $75 / 0 / 0$ & $35 / 0 / 15$ & $10 / 0 / 20$ & $24 / 30$ \\
\hline 8 & BIIla & None & None & NED & $110 / 0 / 0$ & $35 / 0 / 35$ & $40 / 0 / 50$ & $27 / 30$ \\
\hline 9 & BIIIa & $\begin{array}{l}\text { Post-operative shortening of } \\
\text { the rotated limb by } 2 \mathrm{~cm}\end{array}$ & None & NED & $80 / 0 / 0$ & $30 / 0 / 30$ & $10 / 0 / 25$ & $25 / 30$ \\
\hline 10 & BIIla & None & None & NED & $80 / 0 / 0$ & $20 / 0 / 15$ & $30 / 0 / 25$ & $24 / 30$ \\
\hline 11 & BIIla & $\begin{array}{l}\text { Haematoma with temporary } \\
\text { total paresis and sensory loss } \\
\text { Post-operative shortening of } \\
\text { the rotated limb by } 6.5 \mathrm{~cm}\end{array}$ & Drainage of haematoma & NED & $90 / 0 / 0$ & $20 / 0 / 10$ & $10 / 0 / 10$ & $23 / 30$ \\
\hline 12 & BIIla & None & None & NED & $100 / 0 / 0$ & $35 / 0 / 30$ & $20 / 0 / 25$ & $25 / 30$ \\
\hline 13 & BIIla & None & None & NED & $60 / 0 / 0$ & $20 / 0 / 10$ & $15 / 0 / 10$ & $19 / 30$ \\
\hline 14 & BIIla & Fracture of the proximal tibia & Shortening of the proximal fibula & NED & $85 / 0 / 0$ & $26 / 0 / 15$ & $19 / 0 / 18$ & $24 / 30$ \\
\hline 15 & BIIla & $\begin{array}{l}\text { Haematoma and compartment } \\
\text { syndrome }\end{array}$ & $\begin{array}{l}\text { Pressure relief procedure and } \\
\text { above-knee amputation }\end{array}$ & NED & $\mathrm{N} / \mathrm{A}$ & N/A & N/A & N/A \\
\hline 16 & BIIla & None & None & NED & $80 / 0 / 0$ & $20 / 0 / 20$ & $20 / 0 / 20$ & $24 / 30$ \\
\hline 17 & BIIla & None & None & NED & $60 / 0 / 0$ & $15 / 0 / 15$ & $10 / 0 / 10$ & $24 / 30$ \\
\hline 18 & BIIla & None & None & DOD & $90 / 0 / 0$ & $25 / 0 / 25$ & $18 / 0 / 20$ & $\mathrm{~N} / \mathrm{A}$ \\
\hline
\end{tabular}

* NED, no evidence of disease; DOD, died of disease

$\dagger$ because of recurrence of tumour and deteriorated physical condition 
Furthermore, in the two patients (cases 13 and 15) with the worst functional outcome of those who had undergone type BIIIa rotationplasty the operative procedure did not affect their post-operative function. Indeed, compartment syndrome, which led to an above-knee amputation in one of these patients (case 15) could just as well have complicated type BI rotationplasty. The palsy of the sciatic nerve which was responsible for reduced function in one patient (case 13) was present pre-operatively and not a complication of the type BIIIa rotationplasty. The compartment syndrome which led to an above-knee amputation in another patient (case 15) was a major complication affecting the functional result. Finally, no patient in either group had symptoms of degenerative joint disease.

These results raise the question as to whether the knee should be preserved in children with a tumour of the proximal femur. We believe that the functional results of type BIIIa rotationplasty are superior to those of type BI rotationplasty in which the knee is preserved and justify the use of the former in tumours of the proximal femur. However, the limited number of patients in the study do not allow statistical analysis. We therefore report our findings and conclusion and hope that these will be confirmed by additional similar studies in the future.

No benefits in any form have been received or will be received from a commercial party related directly or indirectly to the subject of this article.

\section{References}

1. Winkelmann W. Hip rotationplasty for malignant tumors of the proximal part of the femur. J Bone Joint Surg [Am] 1986;68-A:362-9.
2. Winkelmann W. Type-B-IIla rotationplasty: an alternative operation for the treatment of malignant tumors of the femur in early childhood. J Bone Joint Surg [Am] 2000;82-A:814-27.

3. Winkelmann W. Rotationplasty. Orthop Clin North Am 1996;27:503-23.

4. Hanlon M, Krajbich JI. Rotationplasty in skeletally immature patients: long-term follow-up results. Clin Orthop 1999;358:75-82.

5. Wicart P, Mascard E, Missenard G, Dubousset J. Rotationplasty after failure of a knee prosthesis for a malignant tumour of the distal femur. J Bone Joint Surg $[\mathrm{Br}]$ 2002;84-B:865-9

6. Hillman A, Gosheger G, Hoffmann C, Ozaki T, Winkelmann W. Rotationplasty: surgical treatment modality after failed limb salvage procedure. Arch Orthop Trauma Surg 2000;120:555-8.

7. Borggreve J. Kniegelenkersatz durch das in der Beinlängsachse um $180^{\circ}$ gedrehte Fußgelenk. Arch Orthop Trauma Surg 1930;28:175-8.

8. Van Nes CP. Rotationplasty for congenital defects of the femur. J Bone Joint Surg [Br] 1950;32-B:12-16.

9. Kristen H, Knahr K, Salzer M. Atypical amputations of bone tumors of the lower extremity. Arch Orthop Trauma Surg 1975;83:91-107.

10. Salzer M, Knahr K, Kotz R, Kristen H. Treatment of osteosarcomata of the distal femur by rotationplasty. Arch Orthop Trauma Surg 1981;99:131-9.

11. Hillmann A, Rosenbaum D, Gosheger G, et al. Rotationplasty Type B IIla according to Winkelmann: EMG and gait analysis. Clin Orthop 2001;384:224-31.

12. Hillmann A, Rosenbaum D, Schröter J, et al. Electromyographic and gait analysis of forty-three patients after rotationplasty. J Bone Joint Surg [Am]2000;82-A:187-96.

13. Winkelmann W. Classification of rotationplasty. Campbell's operative orthopaedics. 1992:8:208.

14. Enneking WF, Dunham W, Gebhardt MC, Malawer M, Pritchardt DJ. A system for the functional evaluation of reconstructive procedures after surgical treatment of tumors of the musculoskeletal system. Clin Orthop 1993;286:241-6.

15. Schiller C, Windhager R, Fellinger EJ, et al. Extendable tumour endoprostheses for the leg in children. J Bone Joint Surg [Br] 1995;77-B:608-14.

16. Gottsauner-Wolf F, Kotz R, Knahr K, et al. Rotationplasty for limb salvage in the treatment of malignant tumors of the knee: a follow-up study of seventy patients. J Bone Joint Surg [Am] 1991;73-A:1365-75.

17. Hillmann A, Hoffmann C, Gosheger G, Krakau H, Winkelmann W. Malignant tumor of the distal part of the femur or the proximal part of the tibia: endoprosthetic replacement or rotationplasty: functional outcome and quality-of-life measurements. J Bone Joint Surg [Am] 1999;81-A:462-8. 